\title{
The wisdom of the crowd
}

A new typology for crowdsourcing

Dr Helen K. Liu from the
National Taiwan University
provides a typology for
crowdsourcing public
services based on theories
of coproduction, public
sector volunteerism, and
government-citizen relations.
Having carried out an extensive
review of existing literature
on crowdsourcing, she
systematically examined the
fundamental concepts applied
to defining the role of citizens
engaged in crowdsourcing
practices in the public sector.
The resulting typology
can help policymakers and
designers clarify the functions
of crowdsourcing adoption,
reducing misunderstanding
between governments and
citizens. Furthermore, this
typology will allow the field to
build knowledge systematically
and collectively.

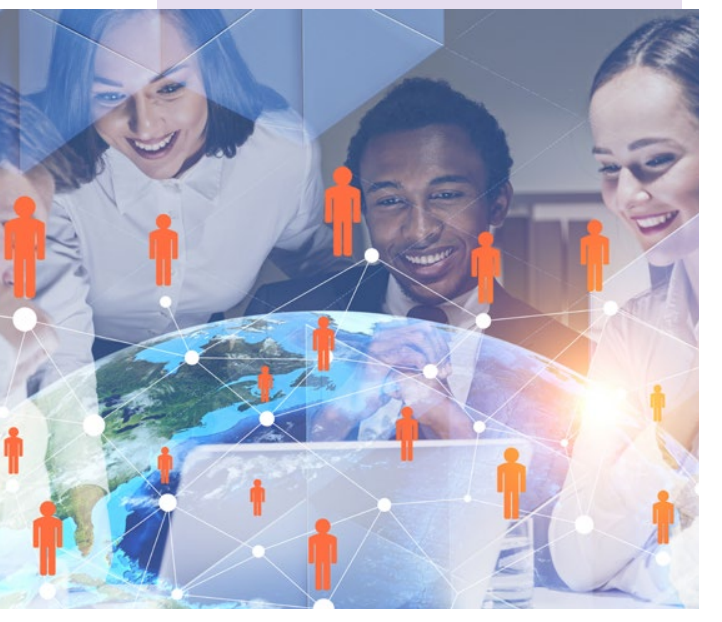

CROWDSOURCING GOVERNMENT Crowdsourcing government describes a governments' efforts in incorporating citizens in the coproduction of public services and policies through technology Lu's work is the fist stream of res. Dr that considers the design principles f adoting crowdsourcing in the public sector. It has already proved to be a breakthrough, both in terms of introducing this open innovation. to the public sector and providing practical solutions that enabled public sector employees to implement crowdsourcing projects.

CONSOLIDATING THE

THEORETICAL BASIS In the course of this research, Dr Liu carried out an extensive review of existing literature on crowdsourcing. She systematically examined the fundamental concepts applied to defining the role of citizens engaged in crowdsourcing she was able to identify the Fsential theories required to consolidate the theoretical ground underpinning crowdsourcing - such as coproduction, public sector volunteerism, and direct public engagement via new forms of technologies and social media.

Coproduction involves citizens working in partnership with government to improve both the quality and effectiveness of policies. It involves public participation in the delivery of government services. Coproduction has been observed to enhance relationships between citizens and government. It creates synergy between the policy work being carried out by citizens and government, as bo

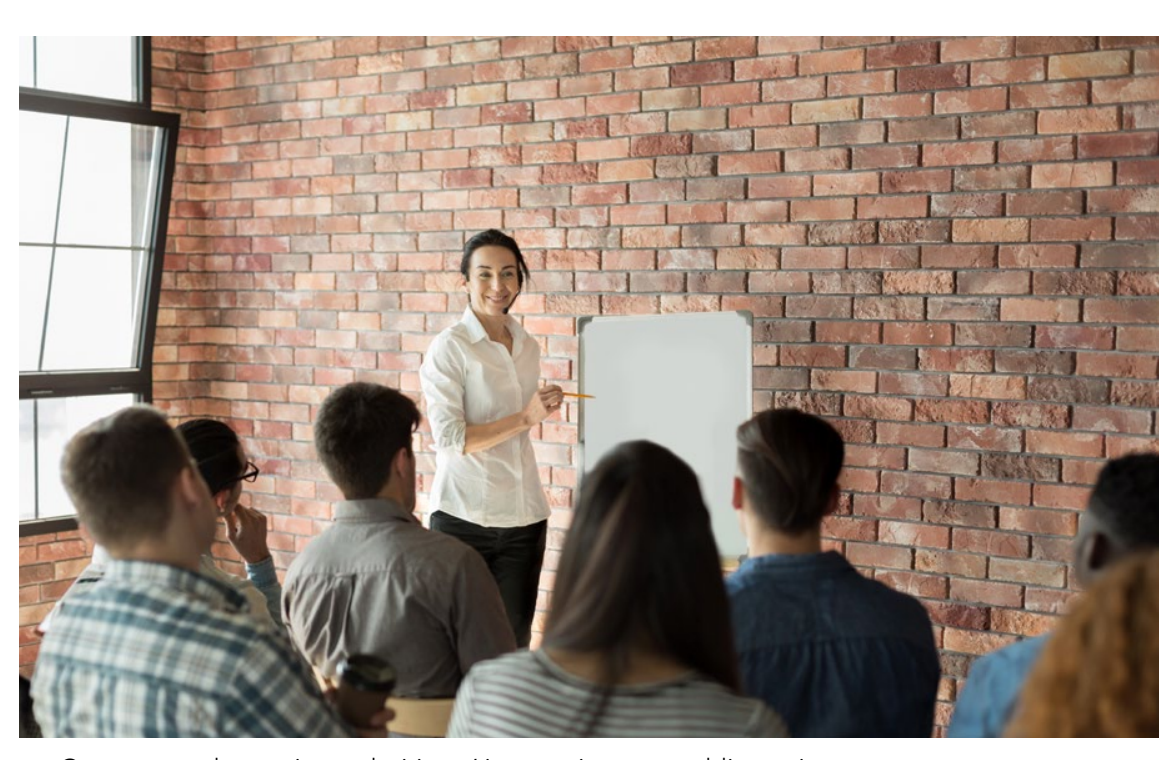

service efficiency and effectiveness. In governments with user-generate contrast, crowdsourcing involves only its geographical data and enables translation senice users and incorporates a broder scope of participants.

In the public sector, crowdsourcing requires an open call for participants to contribute jobs to be performed during crises. Crowdsourcing is also recognised as a form of public engagement Technologr such as in wiki planning, SeeClickFix and participatory budgeting, has the potential to enhance the design of online. It can be viewed as a type of Volunteers are
already involved Dr Liu's work is the first stream of already involved in health, welfare, environmental research that considers the design resources, parks and principles of adopting crowdsourcing in recreation within

the government sector. Crowdsourcing, however, provides a new the public sector. recent study revealed that information
communication technology (ICT) can

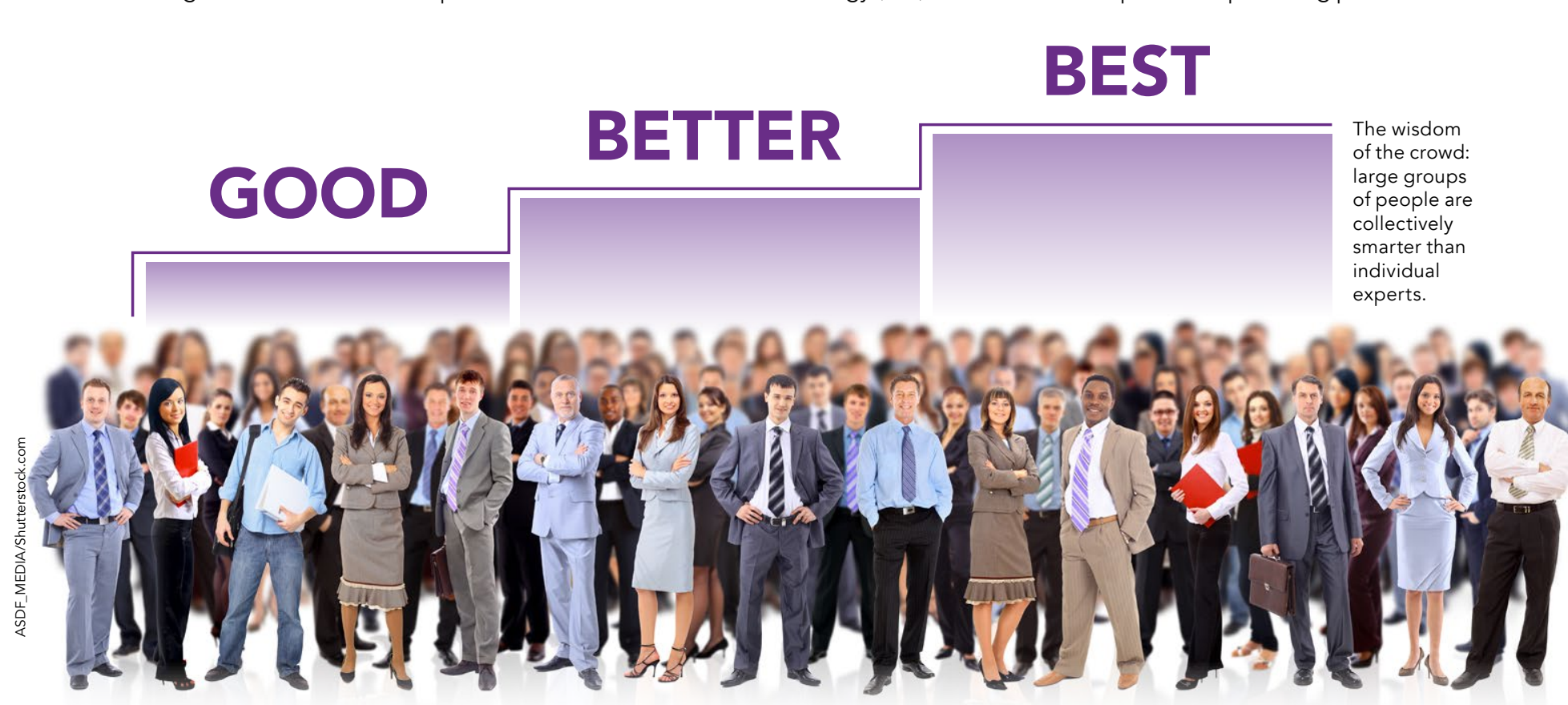

A TYPOLOGY FOR CROWDSOURCING

The literature revealed different categories conceptualising crowdsourcing in the public sector. Dr Liu found two enabled her to construct a typology: the policy stage and the functionality of citizens' effort. Through this, she complementary crowdsourcing in crowdsourcing in senvice implementary complementary crowdsourcing in policy design; and supplementany When a goven the crowd and directly incorporates that input into policy decision-making the government's provision of senvices or policymaking. On the other hand, crowdsourcing is supplementary when information and inputs obtained from citizens are not directly incorporated into a decision-making, but are used as a reference
or in support of the government's provision of services.

CASE STUDIES presents four case studies based 


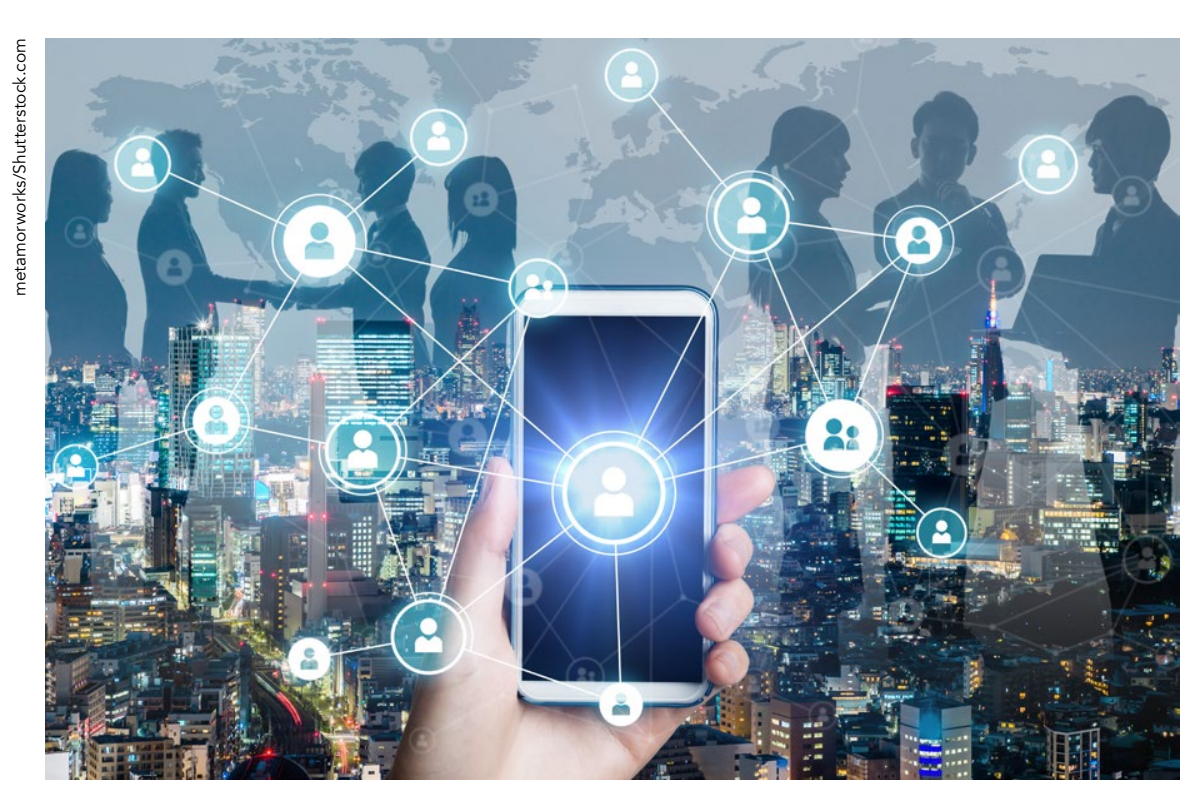

Websites such as SeeClick ix have the potential to enhance the design of effective direct

policy and services and the function of citizens' inputs. For each case, evidence documents, inteniews, and web content analysis. The cases were selected using theoretical sampling.

First, in complementary crowdsourcing in service implementation, citizens are involved in implementing services through a complementary task, but not in designing policy. Here, governments also seek citizens' efforts and incorporate their inputs into service provisions

In the Peer to Patent case, citizens were involved in patent review. Dr Liu studied a joint project by New York University and the United Stres Ptent and Trade the aim of coproducing patent review senvices. Previously, reviewers lacked knowledge and timely access to sufficient information resulting in a huge backlog. This pilot involved many volunteer reviewers who conducted research and reviews through the online PTP platform. The citizens' diverse knowledge of the latest inventions together with their access to a wider range of databases complemented the limitations of the patent office's own review process. This coproduced patent review system was observed to improve both the efficien and effectiveness of the patent review. Second, in supplementary crowdsourcing in service implementation, citizens can

be used to improve public services without providing essential services. Archives Records Adninationa Archivist initiative Citinistration Citzens training so that they could transcribe and classify documents and records th are maintained and preserved by the government. This involvement of citizens efforts has improved the quality of digitalisation, even though the citizens do not directly provide digitalising services.

In complementary crowdsourcing in policy design, citizens are involved in the also provids a broader range of solutions the work to an individual company.

Lastly, supplementary crowdsourcing in policy design involves using citizens inputs as a reference in policy design. The citizens' inputs serve only as references for policymakers and not part of the policy itself. Dr Liu reviewed the UK Department of Energy and Climate Change (DECC) My2050 project. The My2050 simulation allows the public to express their preferences and actions related to energy policy. It provides reference points and import preferences facilitating the DECC's understanding of public opinion abo various energy options and policies.

\section{CITIZENS AS COPRODUCERS}

Dr Liu's typology redefines the roles of and citizens. It demonstrates that the more a government views citizens as coproducers, the more crowdsourcing activities can become complementary Moreover, citizens can have a greater impact on policy design and become more involved in the implementation of services. This typology can help policymakers and designers clarify the functions of crowdsourcing adoption, reducing misunderstanding between governments and citizens. Designing
crowdsourcing based on citizen

Designing crowdsourcing based on citizen and government relationships helps designers align goals and tasks to the right coproducers.

policy design of a complementary task. and government relationships helps The citizens' innovative ideas contribute designers align goals and tasks to the directly to policymaking or public senvice right coproducers. It also enhances. design. These involve challenges or relationships, promoting democracy idea competitions where citizens are building. Furthermore, this typology invited to contribute innovative solutions will allow the field to build knowledge to a specific issue or problem. Dr Liu systematically and collectively. and Space Administration's (NASA) Centennial Challenges which invite citizens, universities, research institutions, and private firms to provide solutions to technical problems. This adoption of complementary crowdsourcing provides

Dr Liu has published a series of manuscripts that help governments to anticipate crowds behaviours. She has also been invited to train and provide consultations for civil servants from sever countries
initiatives.

\section{- Behind the Research} Dr Helen K. Liu

E: helenliu4@gmail.com T: $+886-937-869-717 \quad$ T: $+886-2-3366-8382 \quad$ W: helenliu4.wordpress.com/

Research Objectives

Dr Liu provides a typology for crowdsourcing public services based on theories of coproduction public sector volunteerism, and government-citizen relations.

\section{Detail}

\section{Address}

No. 1, Sec. 4, Roosevelt Road

Taipei, 10617

Bio

Dr Helen K. Liu is an Associate Professor in the Department of Political Science at the National Taiwan University, with a PhD from Indiana University-Bloomington. Recently, Dr Liu was awarded the 2020 MOST Outstanding Research Award. Her primary research interests are in interorganisational networks, social service provision, collaborative governance, crowdsourcing adaptation, and nonprofit management.

Funding

 - Ministry of Science and Technology, R.O.C., Taiwan
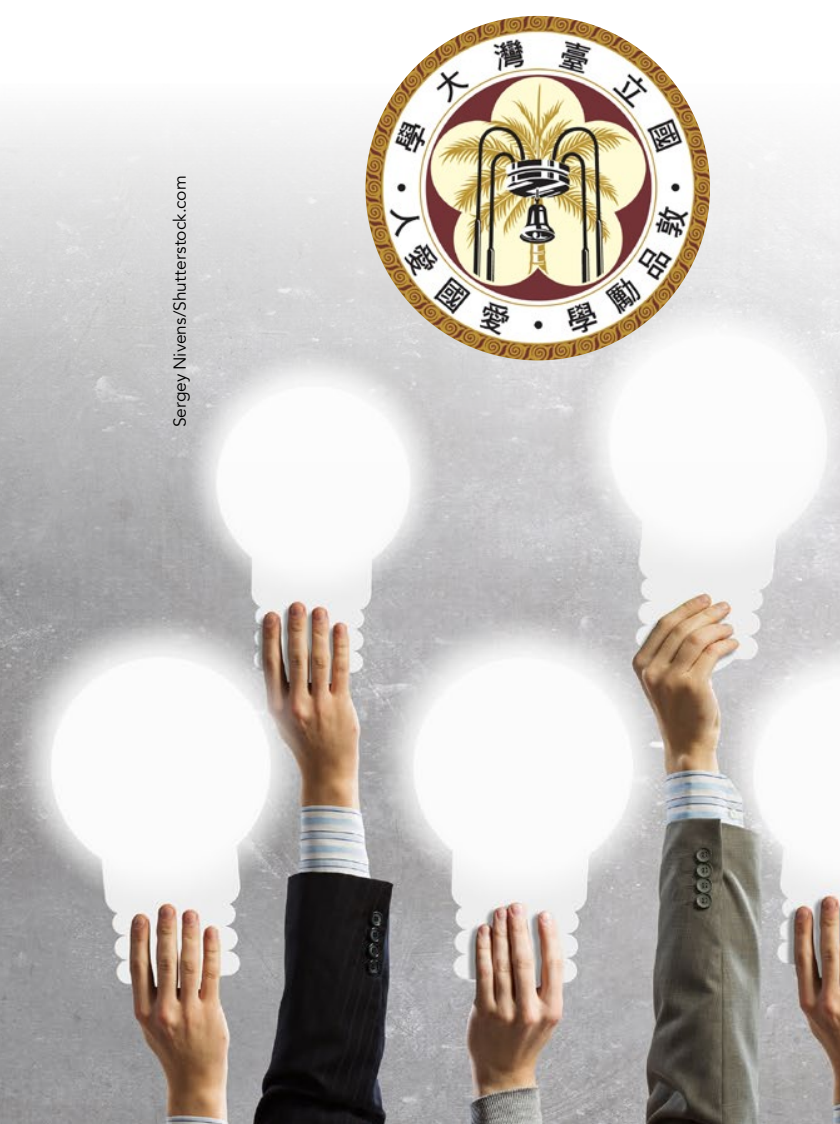

\section{References}

Liu, H. K. (2021). Crowdsourcing: Citizens as Coproducers of Public Services. Policy \& Internet, 1-17. Available at: https://onlinelibrary.wiley.com/doi/10.1002/poi3.249

Liu, H. K. (2017). Crowdsourcing Government: Lessons from Multiple Disciplines. Public Administration Review. Avaliable at: https://onlinelibrary.wiley.com/doiffull/10.1111/puar.1280

Liu, H. K. (2016). An Analysis of the Social Process in Ideas Generation for Public Policies. Proceedings of the $17^{\text {th }}$ International Digital Government Research Conference on https://dl.acm org/doi/10 1145/2912160 2912198

Liu, H. K. (2016). Exploring Online Engagement in Public Policy Consultation: The Crowd or the Few? Australian Journal of Public Administration, 76(1), 33-47. Available at: https://. onlinelibrary.wiley.com/doi/full/10.1111/1467-8500.12209

\section{Personal Response}

What has been the most rewarding outcome of your work so far?

II The most rewarding outcome of this research

is to see the transformation of the public sector to rewarding to exchange experiences and concerns with civil servants from Bangladesh, Cambodia, Fiji, India, Indonesia, IR Iran, Lao PDR, Malaysia, Mongolia, Nepa Pakistan, Philippines, Thailand, Japan, and Taiwan crowdsourcing. For instance, it was fulfilling as a speaker of the International Conference in Tagaytay, Philippines to witness over 600 regional and central civil servants eager to obtain new knowledge on how to transform the public sector in the age of innovation. 